\title{
SIMULASI DAN PEMBUATAN RANGKAIAN SISTEM KONTROL PENGISIAN BATERAI UNTUK PEMBANGKIT LISTRIK TENAGA SURYA
}

\author{
Handy Indra Regain Mosey ${ }^{1)}$ \\ ${ }^{1)}$ Program Studi Fisika FMIPA Universitas Samratulangi Manado \\ e-mail: cici.heijie@gmail.com
}

\begin{abstract}
ABSTRAK
Paper ini membahas tentang simulasi dan pembuatan rangkaian sistem kontrol pengisian baterai yang bersumber dari sebuah pembangkit listrik tenaga surya (Panel Surya). Pengisian baterai yang terlalu lama pada sebuah instalasi pembangkit listrik tenaga surya akan menyebabkan baterai cepat rusak sehingga dibutuhkan sebuah sistem yang dapat berfungsi sebagai pengontrol. Metode penelitian yang dilakukan yaitu dengan merangkai rangkaian yang didapat dari pustaka kemudian disimulasikan dengan perangkat lunak Proteus ISIS Profesional, selanjutnya dilakukan pembuatan rangkaian elektronika dalam sebuah PCB. Tegangan yang dihasilkan oleh baterai dibaca oleh sistem kontrol kemudian sistem akan memilih apabila tegangan yang diberikan oleh panel surya akan diisi pada baterai atau dialihkan kepada sebuah beban tambahan. Hasil yang didapatkan dalam penelitian menunjukan bahwa sistem kontrol pengisian baterai yang dibangun telah bekerja sesuai dengan simulasi dan dapat bekerja dengan baik.
\end{abstract}

Kata-kata kunci: sistem kontrol baterai, switch, panel surya.

\section{SIMULATION AND CONSTRUCTION OF A BATTERY CHARGING CONTROLLER SYSTEM FOR SOLAR POWER PLANTS}

\begin{abstract}
This paper discusses about circuit simulation and construction of a battery charging control system from a solar power plant (Solar Panels). Charging the battery for too long on an installation of solar power plants will cause the battery to be broken and so we need a system that can function as a controller. The research method is made by simulating a baterry charging control circuit from a reference and then simulated by Proteus ISIS Professional software, then constructing the circuit on a PCB. The voltage produced by the solar panel is read by the control system then the system will prefer if the voltage supplied by the solar panels will be filled on the battery or transferred to an additional load. Result obtained in this study indicate that the baterry charging control system are working in accordance with the software simulation and can work as a baterry charging control system for a solar panel instalation.
\end{abstract}

Keywords: Baterry charging control, switch, solar panel.

\section{PENDAHULUAN}

Energi surya fotovoltaik dapat digunakan untuk menyalakan peralatan listrik seperti pompa air, televisi, telekomunikasi, dan lemari pendingin di daerah yang belum terjangkau oleh jaringan listrik PLN. Foton sinar matahari akan diubah menjadi arus listrik oleh sel-sel fotovoltaik. Arus listrik dari panel surya kemudian diarahkan menuju controller dan dipergunakan untuk mengisi baterai sebagai tenaga cadangan ketika energi matahari kurang mencukupi. Selain itu controller juga berfungsi agar tegangan yang dihasilkan menjadi stabil pada tegangan kerja yang diharuskan. Energi listrik yang dihasilkan dapat secara langsung digunakan untuk peralatan listrik yang membutuhkan arus searah atau DC (Hamdi, 2014).

Disamping energi surya memiliki keunggulan, tidak dipungkiri bahwa energi surya dibeberapa tempat seperti Indonesia memiliki kelemahan seperti letak georafis menyebabkan karakteristik penerimaan cahaya matahari dan angin menjadi berbeda- 
beda (Pakpahan, 2000). Semakin jauh letak tempat dari garis ekuator maka fluktuasi lama penyinaran akan semakin besar (Lakitan, 1994).

Untuk mengatasi hal itu diperlukan desain peletakan modul pembangkit listrik tenaga surya yang sesuai dengan kondisi geografis di Indonesia. Selain itu diperlukan perancangan sistem kontrol baterai agar daya yang dihasilkan oleh panel surya dapat digunakan lebih efisien (Ragheb, 2009).

Berdasarkan hal di atas maka akan dilakukan penelitian untuk membuat sistem kontrol baterai yang dapat digunakan pada panel surya. Tahapan dalam penelitian ini yaitu: (1). Akan dibuat sistem kontrol pengisian baterai dengan simulasi menggunakan perangkat lunak Proteus ISIS berdasarkan rangkaian yang didapat dari pustaka, lalu (2). Akan dibuat sistem kontrol pengisian baterai, yang selanjutnya direncanakan akan diujicobakan pada sebuah panel surya.

\section{TINJAUAN PUSTAKA}

Sistem kontrol pengisian baterai sangat diperlukan pada instalasi pembangkit listrik tenaga surya (Piggot, 1995). Pengisian baterai terus-menerus dan berlebihan dapat merusak sel kering baterai (www.panelsurya.com/index.php/id/solarcontroller/12-solar-charge-controller-solarcontroller). Pada penelitian ini akan dirancang sistem pengisian baterai menggunakan beban tambahan. Fungsi dari beban tambahan ini adalah sebagai pengalihan pemberian daya dari sel surya ke baterai yang sudah penuh sehingga pembangkit listrik tenaga surya tetap terbebani tanpa harus selalu membuat pembangkit mengisi baterai yang telah penuh. Beban tambahan ini berupa heater karena dapat menampung daya yang besar. Namun sebelum diujicobakan, digunakan beban tambahan berupa lampu LED. Keadaan panel surya tanpa beban sangat beresiko merusak panel surya itu sendiri. Selain itu fungsi dari sistem pengisian baterai ini adalah sebagai alat monitoring keadaan baterai (penuh atau tidak penuh).

Sistem kontrol pengisian baterai digunakan untuk mencegah baterai mengalami pengisian terlalu lama (Ragheb, 2009). Disamping itu sistem ini membuat pembangkit tetap terbebani saat beroperasi.
Sistem ini bekerja dengan memonitor tegangan baterai 15 VDC sebagai indikator penuh atau tidaknya baterai. Sebelumnya diatur batas tegangan atas indikator baterai penuh adalah 14,8 Volt dan batas tegangan bawah adalah 11,95 Volt. Pengaturan ini dilakukan dengan asumsi bahwa pengisian baterai bersifat transien terhadap waktu sehingga tegangan baterai akan butuh waktu yang lama sampai mencapai tegangan maksimumnya. Jika tegangan baterai lebih besar atau sama batas tegangan atas maka tegangan akan dibebani dummy load, jika tegangan baterai lebih kecil atau sama batas tegangan bawah maka dilakukan pengisian baterai. Untuk tegangan ambang 11,95 Volt $<\mathrm{V}_{\text {baterai }}<14,8$ Volt, pengisian baterai atau pembebanan ke dummy load akan ditentukan oleh user dengan menekan switch on-off pada kontrol. Berikut diagram alir cara kerja rangkaian (Gambar 1).

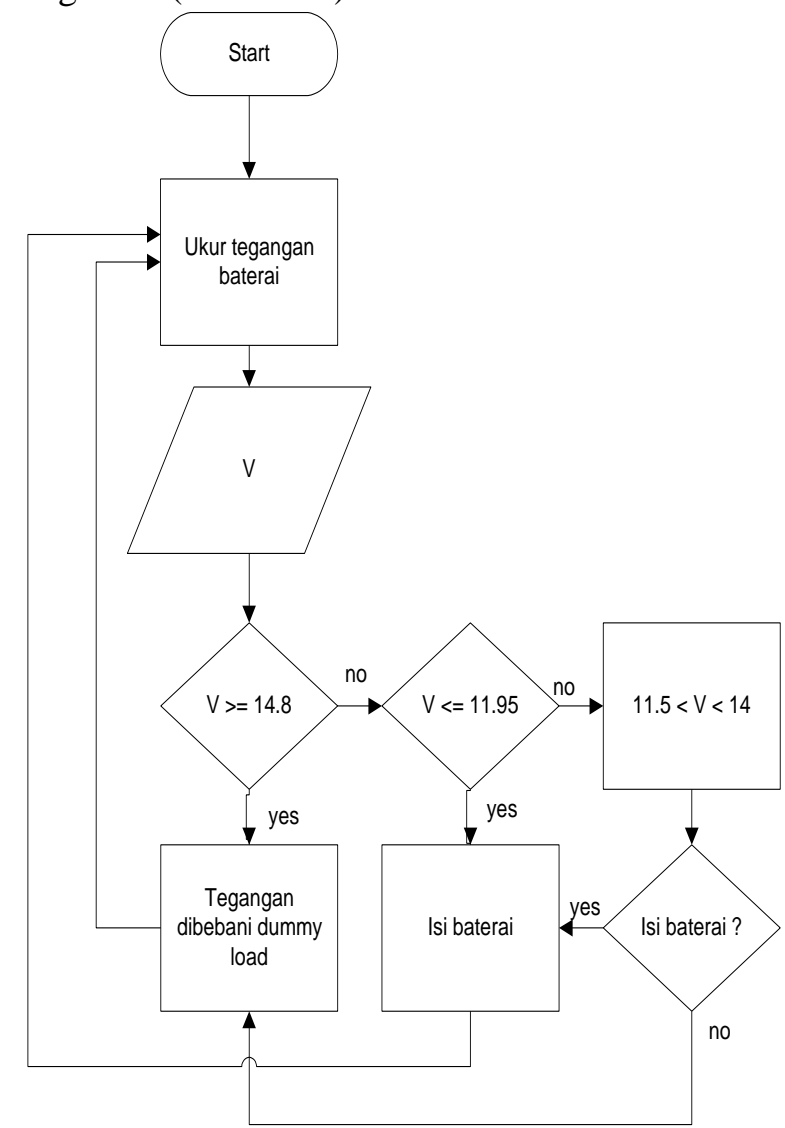

Gambar 1. Diagram alir kontrol pengisian baterai

\section{HASIL DAN PEMBAHASAN}

Gambar 2 menunjukan skematik rangkaian dan hasil simulasi rangkaian 
menggunakan software Proteus ISIS 7 Professional.

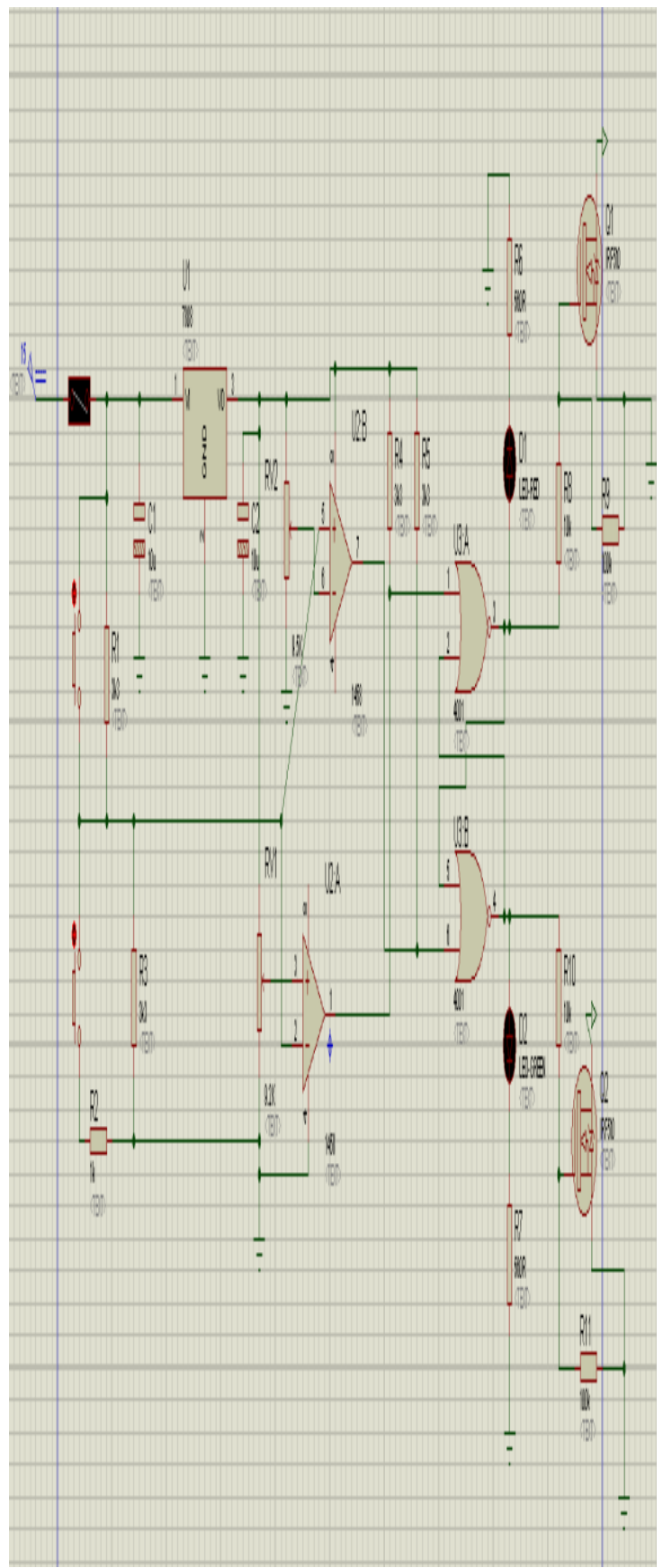

Gambar 2. Desain Rangkaian Sistem Kontrol Pengisian Baterai.

Rangkaian pada gambar 2 bekerja dengan cara memonitor masukan tegangan 15 volt dari baterai. Tegangan dari baterai ini dapat berubah ketika tegangan baterai mulai menurun. Pada gambar juga terlihat adanya regulator tegangan 8 Volt (LM7808), sehingga tegangan masukan terbagi menjadi 8 Volt dan 7,5 Volt pada saat baterai penuh dan ketika baterai tidak penuh bernilai 8 Volt dan 5,75 Volt. Rangkaian ini bekerja dengan menggunakan Op-Amp dalam hal ini komparator LM 339N sebagai pembanding tegangan yang masuk dari dua resistor variable (RV1 dan RV2) yang telah ditetapkan nilainya yaitu 7,4 Volt dan 5,95 Volt. Selanjutnya komparator akan membandingkan tegangan ketika baterai penuh masukannya bernilai 7,5 Volt (pada kaki 3 dan 6) dan ketika baterai tidak penuh maka tegangannya bernilai 5,75 Volt. Selanjutnya tegangan akan melalui gerbang NOR yang dibuat secara latch untuk mengaktifkan lampu LED, MOSFET dan relay.

Dari skematik rangkaian, selanjutnya dilakukan simulasi rangkaian dengan menggunakan bantuan perangkat lunak Proteus ISIS 8 Profesional. Dari gambar 3 terlihat lampu hijau D2 menyala (baterai terbebani ke dummy load). Dari gambar 4 terlihat lampu merah D1 menyala (baterai terbebani ke dummy load).

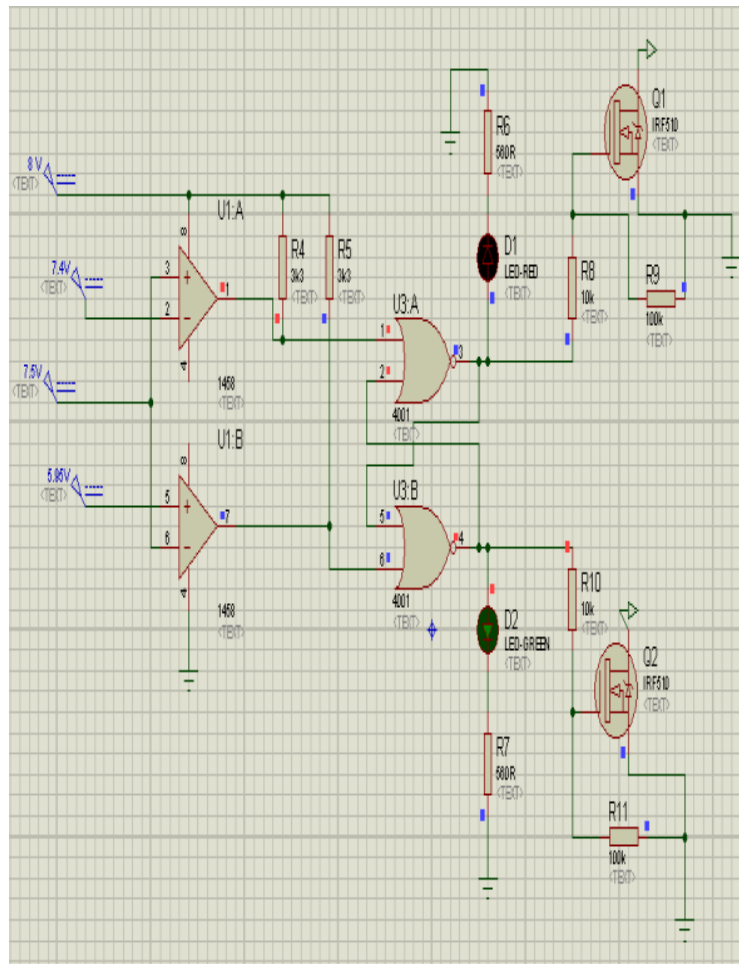

Gambar 3. Simulasi rangkaian kontrol pengisian baterai. Tegangan baterai penuh hingga mencapai 15-15,5 VDC. Lampu hijau menyala (baterai terbebani ke dummy load). 


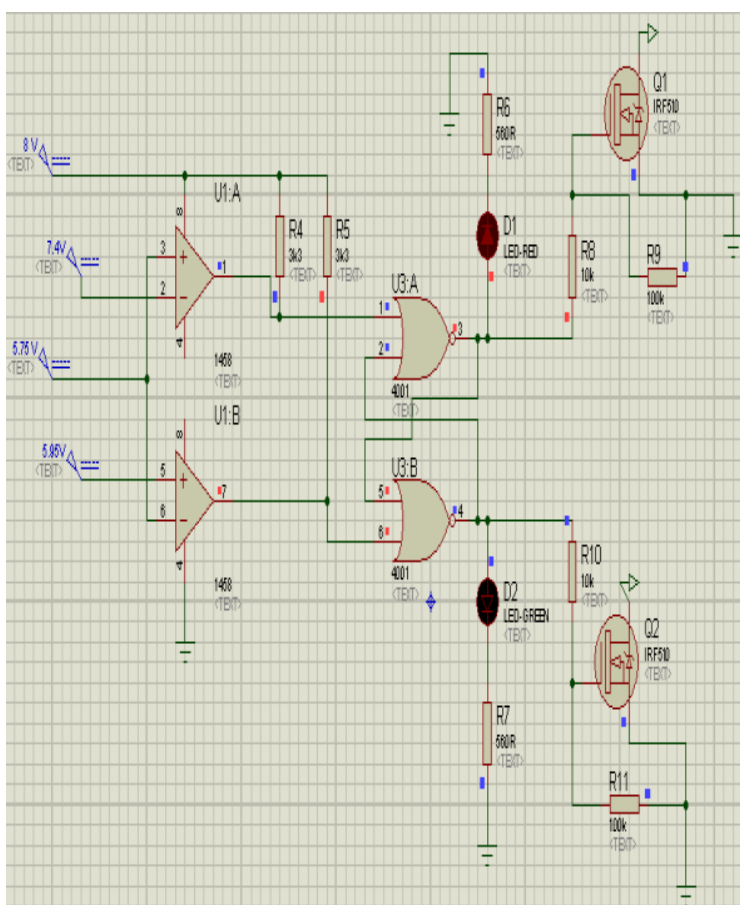

Gambar 4. Simulasi rangkaian kontrol pengisian baterai. Tegangan baterai jatuh hingga mencapai 11.5 VDC. Lampu merah menyala (dilakukan pengisian baterai)

Setelah disimulasikan, penelitian dilanjutkan dengan membuat rangkaian sistem kontrol baterai pada sebuah rangkaian PCB. Gambar 5 menunjukan rangkaian yang telah dibuat.

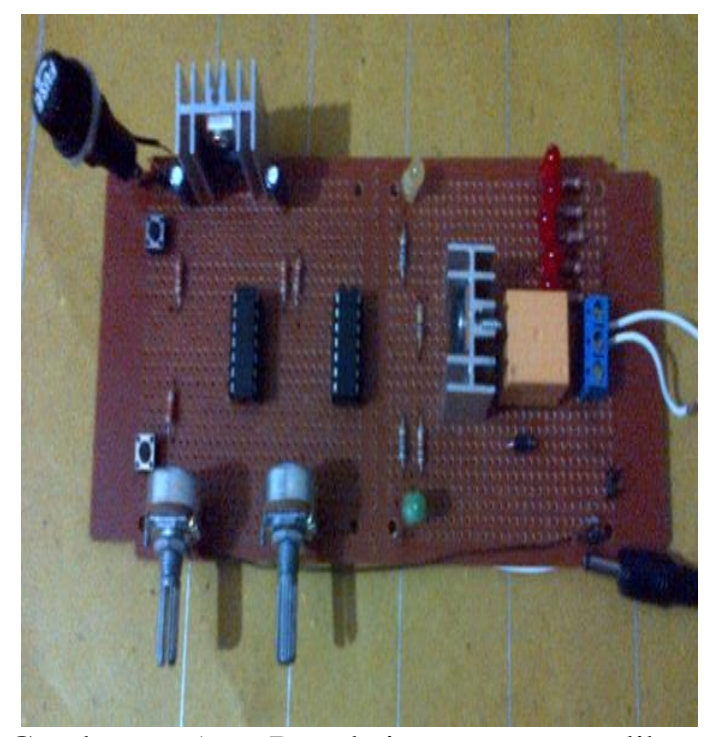

Gambar 5. Rangkaian yang dibuat berdasarkan skema pada gambar 2

Pada gambar 5 terlihat bahwa rangkaian belum terhubung dengan catu daya.

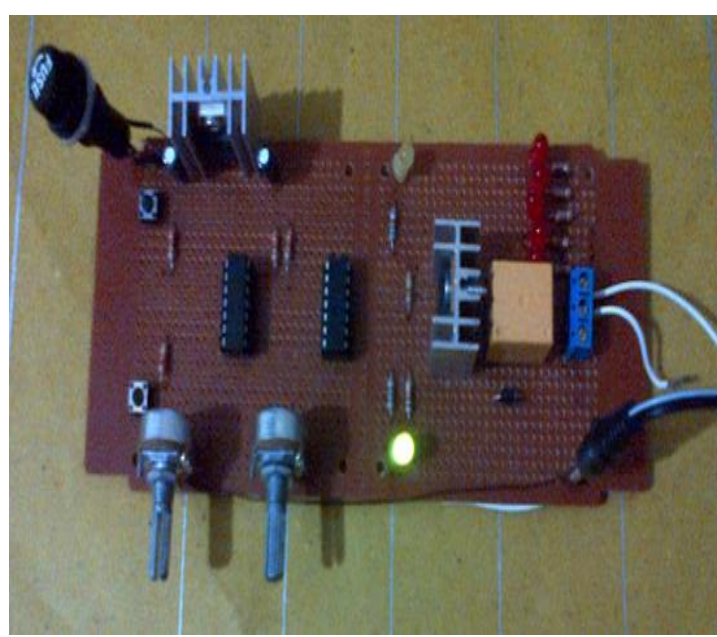

Gambar 6. Lampu hijau menyala ketika rangkaian diberi catu daya 15 VDC atau ketika baterai penuh.

Dalam alat ini yang digunakan sebagai baterai (asumsi) adalah trafo yang bisa diubah-ubah tegangan keluarannya. Ketika masukan dari trafo ke rangkaian bernilai 15 Volt (pada trafo bernilai 12 Volt), maka lampu hijau yang akan menyala (Gambar 6). Ketika masukan dari trafo ke rangkaian bernilai 7,5 Volt (tegangan yang terukur adalah 11,8 Volt), maka lampu kuning secara otomatis akan menyala (gambar 7). Agar lampu hijau menyala lagi, maka input harus dinaikan lagi ke posisi 12 Volt (pada trafo).

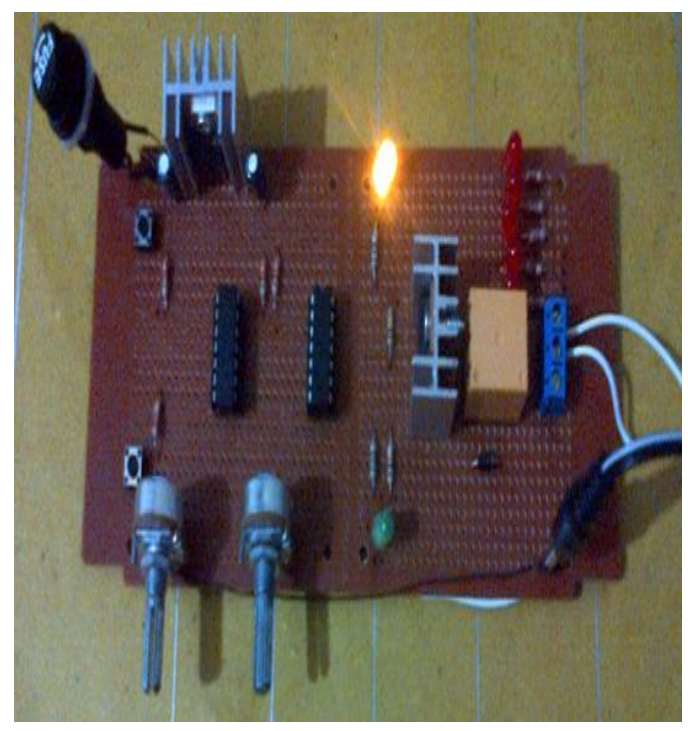

Gambar 7. Lampu kuning menyala, ketika tegangan masukan bernilai 7,5 VDC. 


\section{KESIMPULAN}

Telah berhasil dilakukan simulasi dan pembuatan sistem kontrol pengisian baterai. Sistem kontrol ini bekerja dengan cara memonitor tegangan masukan dari sebuah catu daya (baterai) dan dapat melakukan pengisian secara otomatis apabila tegangan masukan (dari baterai) mulai menurun sesuai dengan nilai yang ditetapkan. Sistem kontrol pengisian baterai telah diuji dan menunjukan unjuk kerja yang baik.

\section{DAFTAR PUSTAKA}

Hamdi, S. 2014. Mengenal Lama Penyinaran Matahari Sebagai Salah Satu Parameter Klimatologi. Berita Dirgantara Vol. 15. No. 1. Juni 2014:7-16.

Lakitan, B. 1994. Dasar-dasar Klimatologi. PT Rajawali Grafindo. Jakarta.

http://www.panelsurya.com/index.php/id/sola r-controller/12-solar-charge-controllersolar-controller.

Pakpahan, Sahat. 2000. Sistem Wind-Diesel untuk Pembangkit Listrik di Lokasi Dengan Kecepatan Angin Menengah Di Indonesia. LAPAN

Piggot, H. 1995. Wind Power Workshop. Centre of Alternative Technology Publication.

Ragheb, M. 2009. Control of Turbinangines. 